\title{
Relationship between Health Expenditure and GDP in Developed Countries
}

\author{
Miniar Ben Ammar Sghari ${ }^{1}$ Sami Hammami ${ }^{2}$ \\ ${ }^{1,}$ Doctor in Economics, Faculty of management and economics, Sfax University, Tunisia. \\ ${ }^{2,}$ Economics Professor, Faculty of management and economics, Sfax University, Tunisia
}

\begin{abstract}
This study uses international health care expenditure per capita data of 30 developed countries from 1975 to 2011 for exploring the causality between the real per capita health care expenditure (HCE) and real per capita GDP. The findings indicate that bidirectional Granger causality is predominant.
\end{abstract}

KEYWORDs: health care expenditure per capita, GDP per capita, developed countries, Granger causality.

\section{INTRODUCTION}

This paper analyzes the causality between the real per capita health care expenditure (HCE) and real per capita GDP in 30 developing countries_ Australia, Austria, Belgium, Canada, Czech Republic, Denmark, Finland, France, Germany, Greece, Hungary, Iceland, Ireland, Italy, Japan, Korea, Luxembourg, Mexico, Netherlands, New Zealand, Norway, Poland, Portugal, Republic of China, Slovak Republic, Spain, Sweden, Switzerland, Turkey, United Kingdom, and United States from 1975 to 2011.Recently, health care economists have devoted a great deal of attention to analyzing the time series pattern of HCE and GDP. Most of the literature on the factors of health care Expenditure growth focuses on the effect of income, usually proxied by per capita Gross Domestic Product (GDP). The aim of this paper is to find out if the long-run relationship between the increase in health care expenditure and economic growth is stable, and probe into their short-run causal relationship and its influence. In addition, the paper aims to know whether the relationship between the two is still positive. These questions have never been discussed in developing countries.

\section{LITERATURE REVIEW}

The relationship between real per capita health care expenditure (HCE) and real per capita income (GDP) has been profusely analysed since the publication of the seminal papers in Kleiman (1974) and Newhouse (1977).These two authors have argued that there is a strong positive correlation between the HCE and GDP of the developed economies. Also, they indicate that the GDP explains a high percentage of the variation of the HCE.In the majority of relevant studies, real per capita healthcare expenditure (HCE) is hypothesized to be a function of real per capita income (GDP) (Hansen and King, 1996; Newhouse, 1987; Parkin et al., 1987; Milne and Molana, 1991; Gerdtham and Jonsson, 1991; Hitiris and Posnett, 1992).Over the last few years, the debate on this link has moved on whether the income elasticity of health care expenditure is greater or less than 1 (Bac and Le Pen, 2002). An income elasticity less than 1 classified health care expenditure and income inelastic, therefore, as a "necessary" good. On the other hand, if the elasticity is higher than 1, health will be classified as a "luxury" good. In summary, the empirical literature on the determinants of health care expenditure shows that aggregate income is one of the most important factors in explaining health care expenditure growth.Fuchs (1996) indicated that $85 \%$ of the scholars in the field of health economics agreed that income is the most important variable of health care expenditure. However, these researchescannot explain the increase in health care expenditure in all countries. Numerous empirical literatures have probed into the international factors affecting health care expenditure; however, they tend to focus on the relationship of health care expenditure with national income. Kleiman (1974) and Newhouse (1977) studied the factors affecting health care expenditure in different countries through a cross-sectional analysis of international data. Also, Newhouse (1977) examined 13 OECD countries and found that income is the most critical factor in the difference in health care expenditure among countries. Parkin et al. (1987) and Gerdthamand Jönsson (1991) aligned medical price and national income with an implicit price deflator and exchange rate. Parkin et al. (1987) studied crosssectional data of 23 OECD countries in 1980 and found that the purchasing power index of medical care could reduce the income elasticity of medical care. Murthy and Ukpolo (1994) conducted an empirical study using time series to ascertain if the data is stationary through unit root and cointegration tests. After conducting the Dickey-Fuller (DF) and Augmented Dickey-Fuller (ADF) tests, 
the results indicated that data is found to be in a non-stationary series. Thus, they probed the factors affecting average individual health care expenditure in the United States using a cointegration test, and the results of regression analysis indicated that the income elasticity of health care expenditure is significantly different from the analytical result obtained from cross sectional data. In addition, Culyer (1990) studied individual OECD countries using pooled data and found a significantly positive correlation between health care expenditure and GDP. However, time-series analysis is related to the stationary series of the variables and spurious regression. Thus, with regard to the empirical approaches of Culyer (1990), Hansen and King (1996) indicate, in their studies, that there is no long-run relationship between health care expenditureand GDP. . Moreover, Gerdtham and Löthgren (2000) studied 20 OECD countries from 1960 to 1997 using Country-byCountry and panel data analysis in order to ascertain the factors affecting health care expenditure. The empirical result of their study suggested that health care expenditure and GDP are non-stationary time series and there is a cointegration between them. In addition, from the theoretical perspective, Hall and Jones (2007) propose a precise analysis on the reason for the increase in the percentage of health care expenditure in GDP. Researchers suggest that health care expenditure is the rational reaction of an economic system to a continuous growth in income. The conclusion is theoretically based on the hypothesis that the reduction rate of marginal utility in consumption is more significant than that of the returns of medical productivity. This paper analyzes the time series properties of per-capita real health care expenditures. For example, Hansen and King (1996) and Blomqvist and Carter (1997) find that HE and GDP are non-stationary. Recently, researchers have begun to favor panel-based unit root tests due to the increase in power that panel tests offer.

\section{METHODOLOGY AND RESULTS}

we construct the long-run relationship between real per capita GDP and real per capita health care expenditure in the following manner:

Yit $=\mathrm{Ai}+\mathrm{BiXit}+$ uit

Yit indicates the per capita GDP of country $i$ at timet.

Xit indicates the per capita health care expenditure of country $i$ at time $t$.

$\mathrm{Ai}$ is the autonomous expenditure,

$\mathrm{Bi}$ is the induced expenditure or the income elasticity of health care expenditure

To infer the causal relationship between per capita HCE and per capita GDP, the Toda and Yamamoto (1995) test for long-run causality was applied. This procedure avoids the problems of testing for Granger causality with respect to the power and size properties of unit root and co-integration tests (Zapata and Rambaldi, 1997). The Toda and Yamamoto (1995) test involves estimation of a vector autoregressive (VAR) model in levels, a method that minimizes the risks associated with incorrect identification of the order of integration of the respective time series and co-integration among the variables. Annual per capita HCE data are available for the period 1975-2011 1 from the 2011 edition of the OECD Health Database. Real per capita GDP data were taken from the World Development Indicators 2011.( Tables 1 )

Table1 : Tests for integration

\begin{tabular}{|l|l|l|}
\hline & Per capita HCE & Per capita GDP \\
\hline Australia & $\mathrm{I}(0)$ & $\mathrm{I}(1)$ \\
\hline Austria & $\mathrm{I}(0)$ & $\mathrm{I}(1)$ \\
\hline Belgium & $\mathrm{I}(0)$ & $\mathrm{I}(1)$ \\
\hline Canada & $\mathrm{I}(2)$ & $\mathrm{I}(1)$ \\
\hline Czech Republic & $\mathrm{I}(0)$ & $\mathrm{I}(0)$ \\
\hline Denmark & $\mathrm{I}(1)$ & $\mathrm{I}(1)$ \\
\hline Finland & $\mathrm{I}(0)$ & $\mathrm{I}(1)$ \\
\hline France & $\mathrm{I}(0)$ & $\mathrm{I}(2)$ \\
\hline Germany & $\mathrm{I}(1)$ & $\mathrm{I}(1)$ \\
\hline Hungary & $\mathrm{I}(0)$ & $\mathrm{I}(1)$ \\
\hline Iceland & $\mathrm{I}(0)$ & $\mathrm{I}(1)$ \\
\hline Ireland & $\mathrm{I}(0)$ & $\mathrm{I}(1)$ \\
\hline Italy & $\mathrm{I}(0)$ & $\mathrm{I}(1)$ \\
\hline Japan & $\mathrm{I}(0)$ & $\mathrm{I}(1)$ \\
\hline Korea & $\mathrm{I}(1)$ & $\mathrm{I}(2)$ \\
\hline Luxembourg & $\mathrm{I}(2)$ & $\mathrm{I}(1)$ \\
\hline Mexico & $\mathrm{I}(1)$ & $\mathrm{I}(1)$ \\
\hline
\end{tabular}




\begin{tabular}{|l|l|l|}
\hline Netherlands & $\mathrm{I}(1)$ & $\mathrm{I}(1)$ \\
\hline New Zealand & $\mathrm{I}(0)$ & $\mathrm{I}(1)$ \\
\hline Norway & $\mathrm{I}(0)$ & $\mathrm{I}(1)$ \\
\hline Poland & $\mathrm{I}(1)$ & $\mathrm{I}(1)$ \\
\hline Portugal & $\mathrm{I}(0)$ & $\mathrm{I}(2)$ \\
\hline Republic of China & $\mathrm{I}(0)$ & $\mathrm{I}(2)$ \\
\hline Slovak Republic & $\mathrm{I}(0)$ & $\mathrm{I}(1)$ \\
\hline Spain & $\mathrm{I}(1)$ & $\mathrm{I}(1)$ \\
\hline Sweden & $\mathrm{I}(2)$ & $\mathrm{I}(0)$ \\
\hline Switzerland & $\mathrm{I}(1)$ & $\mathrm{I}(0)$ \\
\hline Turkey & $\mathrm{I}(1)$ & $\mathrm{I}(0)$ \\
\hline United Kingdom & $\mathrm{I}(0)$ & $\mathrm{I}(1)$ \\
\hline United States & $\mathrm{I}(0)$ & $\mathrm{I}(1)$ \\
\hline
\end{tabular}

Notes: Significantly different from zero at the 0.5 significance level. The optimal lag used for conducting the ADF test statistic was selected based on an optimal Schwarz Bayesian information criterion using a range of lags.

Testing for Granger causality with respect to the power and size properties of unit root and cointegration tests (Zapata and Rambaldi, 1997). The Toda and Yamamoto (1995) test involves estimation of a vector autoregressive (VAR) model in levels, a method that minimizes the risks associated with incorrect identification of the order of integration of the respective time series and co-integration among the variables. Specifically, the Toda Yamamoto long-run causality test artificially augments the correct order of the VAR, k, by the maximum order of integration, dmax, and ensures that the usual test statistics for Granger causality have the standard asymptotic distribution (Wolde-Rufael, 2005).There has been much interest in investigating causality between HCE and GDP. Although HCE is ordinarily hypothesized to be a function of real per capita GDP, there are some reasons which this could be a bilateral relationship, as it can be reasoned that population health is an input to the macroeconomic production function. A modified version of the Granger (1969) causality test proposed by Toda and Yamamoto (1995) was used to test causality between per capita GDP and total per capita HCE in 30 OECD countries over the period 1975-2011. The findings indicate that bidirectional Granger causality is predominant. The study highlights the risk of misinterpreting the relationship between per capita GDP and per capita HCE and the value of considering bilateral causality as a possibility. (Table 2)

Table 2 : Granger non-causality test

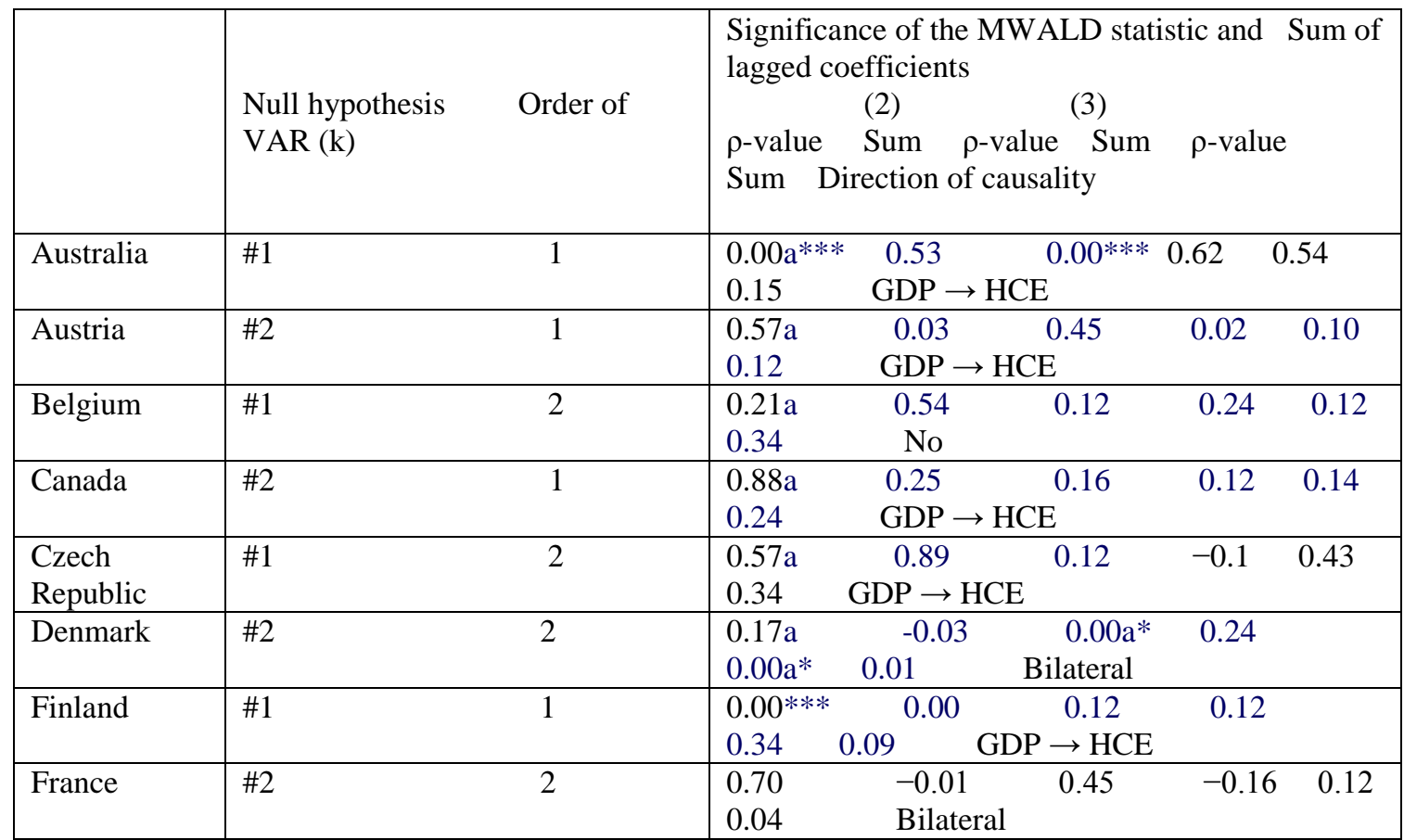


Relationship Between Health Expenditure...

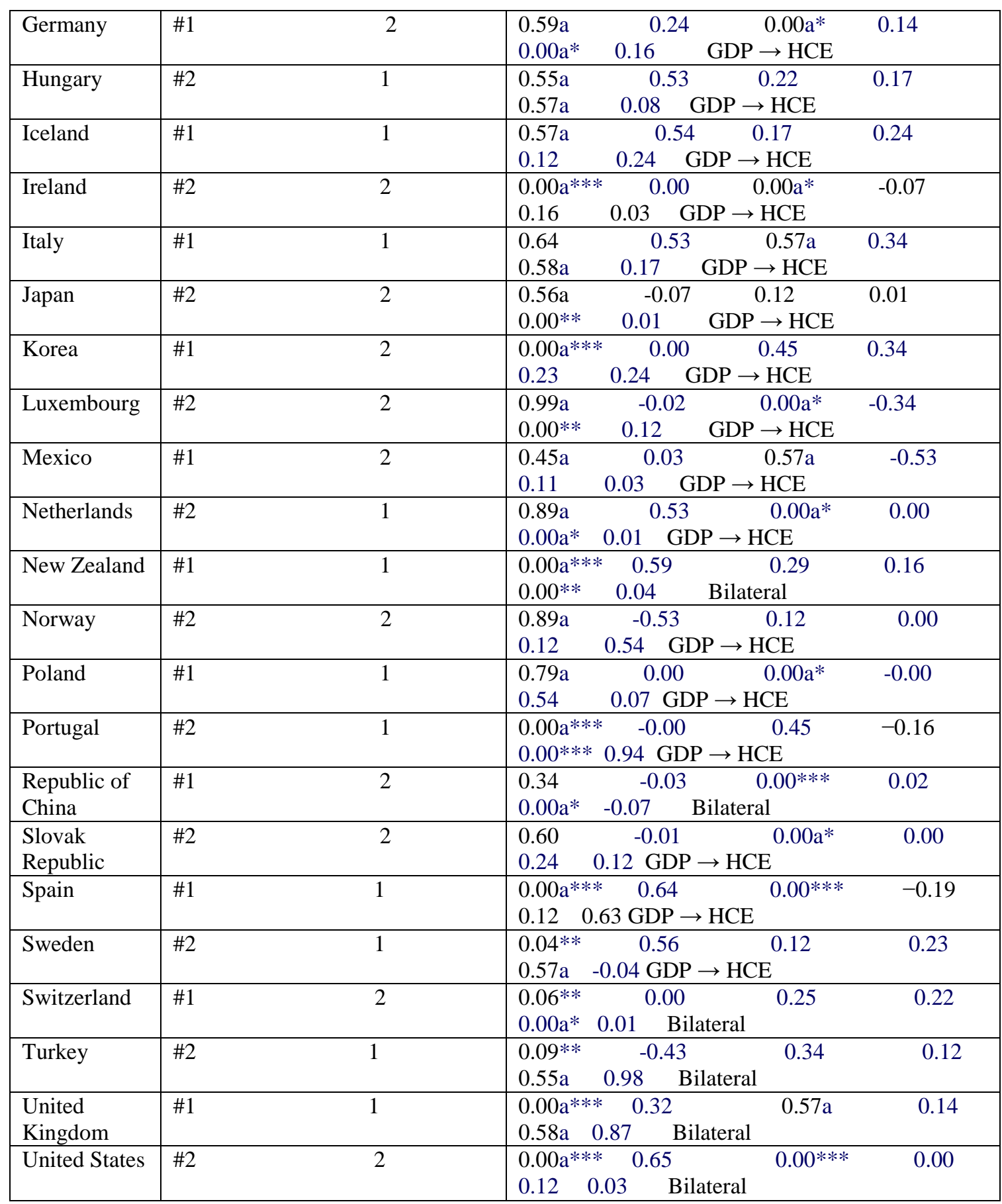

Notes: Significance of the modified Wald chi-square statistics to test whether the k lags are equal to zero (see Kuzozumi and Yamamoto, 2000; Wolde-Rufael, 2005). Numbers

in parentheses denote VAR length ( $\mathrm{k}+\mathrm{dmax})$. The VAR order $(\mathrm{k})$ was selected using the Schwarz Bayesian information criterion.

H0 \#1: GDP does not Granger-cause healthcare expenditure.

H0 \#2: Healthcare expenditure does not Granger-cause GDP.

Sum: sum of lagged coefficients.

* Significant at the $10 \%$ level.

** Significant at the 5\% level.

*** Significant at the $1 \%$ level.

a Denotes the selected optimum lag length of the VAR $(k+d m a x)$. 


\section{REFERENCES}

[1] Barro, R.J., 1991. Economic growth in a cross section of countries. Quarterly Journal of Economics 196, 407-443.

[2] Bloom, D.E., Canning, D., Sevilla, J., 2001. The Effect of Health on Economic Growth: Theory and Evidence, (Working Paper 8587). National Bureau of Economic Research, Cambridge.

[3] Breitung, J., 2000. The local power of some unit root tests for panel data. In: Baltagi, B. (Ed.), Advances in Econometrics, Vol 15: Nonstationary Panels, Panel Cointegration, and Dynamic Panels. JAI Press, Amsterdam, pp. 161-178.

[4] Buchinsky, M., 1998. Recent advances in quantile regression models: a practical guideline for empirical research. Journal of Human Resources 33 (1), 88-126.

[5] Choi, I., 2001. Unit root tests for panel data. Journal of International Money and Finance 20, $249-272$.

[6] Christopoulos, D.K., Tsionas, E.G., 2004. Financial development and economic growth: evidence from panel unit root and cointegration tests. Journal of Development Economics 73, 55-74.

[7] Culyer, T.J., 1990. The Internal Market: An Acceptable Means to a Desirable End, Working Papers 067chedp. University of York, Centre for Health Economics.

[8] Engle, R.F., Granger, C.W.J., 1987. Co-integration and error correction: representation, estimation, and testing. Econometrica 55, 251-276.

[9] Finkelstein, A., 2007. The aggregate effects of health insurance: evidence from the Introduction of Medicare. Quarterly Journal of Medicare $122(1), 1-37$.

[10] Fisher, R.A., 1932. Statistical Methods for Research Workers, 4th Edition. Oliver \& Boyd,Edinburgh

[11] Fogel, R.W., 1997. New findings on secular trends in nutrition and mortality: some implications for population theory. In: Rosenzweig, M., Stark, O. (Eds.), The Handbook of Population and Family Economics,Vol. 1A.NorthHolland,Amsterdam, pp. 433-481.

[12] Fuchs, V.R., 1996. Economics, values, and health care reform. American Economic Review 86 (1), 1-24.

[13] Gerdtham, U., Jönsson, B., 1991. Price and quantity in international comparisons of health care expenditure. Applied Economics 23, 1519-1528.

[14] Gerdtham, U., Jönsson, B., 2000. International comparisons on health expenditure: heory, data and econometric analysis. In: Culyer, A.J., Newhouse, J.P. (Eds.), Handbook of Health Economics. Elsevier Science, North Holland.

[15] Gerdtham, U., Löthgren, M., 2000. On stationarity and cointegration of international health expenditure and GDP. Journal of Health Economics 19, 461-475.

[16] Hall, R.E., Jones, C.I., 2007. The value of life and the rise in health spending. Quarterly Journal of Economics 122 (1), $39-72$.

[17] Hansen, P., King, A., 1996. The determinants of healthcare expenditure: a cointegration approach. Journal of Health Economics $15,127-137$.

[18] Im, K.S., Pesaran, M.H., Shin, Y., 2003. Testing for unit roots in heterogeneous panels. Journal of Econometrics 115, 53-74

[19] Kao, C., 1999. Spurious regression and residual-based tests for cointegration in panel data. Journal of Econometrics 90, 1-44.

[20] Kleiman, E., 1974. The determinants of national outlay on health. In: Perlman (Ed.), The Economics of Health and Medical Care. John Wiley \& Sons, New York. 